\title{
Awareness On Transmission Of Diseases In Chennai Population
}

Research Article

Amrithaashri S ${ }^{1}$, L.Keerthi Sasanka ${ }^{2 *}$,Archana Santhanam ${ }^{3}$

${ }^{1}$ Department of Prosthodontics, Saveetha Dental College and Hospitals, Saveetha Institute of Medical and Technical Sciences Saveetha University, Chennai-600077, Tamilnadu, India.

${ }^{2}$ Senior Lecturer, Department of Prosthodontics, Saveetha Dental College And Hospitals, Saveetha Institute Of Medical And Technical Sciences, Saveetha University, Chennai-600077, Tamilnadu, India.

${ }^{3}$ Senior Lecturer, Department of Oral Pathology, Saveetha Dental College and Hospitals, Saveetha Institute of Medical and Technical Sciences Saveetha University, Chennai-600077, Tamilnadu, India.

\section{Abstract}

The dental clinic is a common healthcare facility in which aerosol particles are spread during various treatments and procedures, through different ways, also by patients. The treatment procedure includes the air polishing, to the operation, scaling by ultrasonic scalers, high and low speed rotate three instruments, using the air water syringe etc. The aerosol which was produced will be a mixture of major particles and fluid containing pathogenic viruses. The study involves random people in any age group, approvals from Institutional Review Board, sampling method is random sampling of hundred participants with 12 questions. The respondents responded that, $57 \%$ of them are aware of the transmission diseases, $51 \%$ of the people are aware that diseases can be transmitted through air or water. $47.5 \%$ of the people are aware that there are five routes of transmission. $50 \%$ of the people are aware that if we drink bacteria water we will get infected. $52 \%$ of the people are aware that they should get fascinated in order to prevent transmission. 52.5\% think that it is good to use antibiotics. The results have proved that well crafted healthy educational campaigns can be effective, the rise of awareness helps to promote good health enhancing practises in resource us who are settings. The risk of exposure to add borne, vector borne and waterborne diseases and harmful to human beings.

Keywords: Awareness; Dental Clinic; Educational Counselling; Transmission.

\section{Introduction}

Economic trends have shaped our growth and the growth of the livestock sector, but at-the expense by altering natural and ancient resources and systems in ways that are not always obvious. Now, however, the reverse is beginning to happen, the environmental trends are beginning to shape our economy and health status of our country. In addition to water, air and food, animals and birds play a pivotal and significant role in the maintenance and transmission of important and essential zoonotic diseases in nature. It is generally considered that the prevalence of waterborne zoonoses and vector-borne is likely to increase in the coming years due to the effects of global warming in India. In recent years, vector-borne diseases have emerged as a serious and important also common public health problem in many countries of the South-East Asia region, including India. Vector- borne zoonoses now occur in epidemic form almost on an annual basis, causing considerable and destroyable morbidity and mortality. New reservoir areas of cutaneous leishmaniasis in South India have been thoroughly recognised, and the role of climate change in its reemergence warrants further research are being going, as does the role of climate change in the ascendancy of waterborne and food-borne illness. Similarly, climate change that leads to warmer and more humid conditions may highly increase the risk of transmission of airborne zoonoses, and hot and drier conditions may lead to a decline in the incidence of the diseases. The prevalence of these zoonotic diseases and their vectors and the effect of cli-

*Corresponding Author:

L. Keerthi Sasanka,

Senior Lecturer, Department of Prosthodontics, Saveetha Dental College And Hospitals, Saveetha Institute Of Medical And Technical Sciences, Saveetha University,

Chennai-600077, Tamilnadu, India.

E-mail: keerthis.sdc@saveetha.com

Received: October 30, 2019

Accepted: November 28, 2019

Published: November 30, 2019

Citation: Amrithaashri S, L.Keerthi Sasanka, Archana Santhanam, Subhashree. R. Awareness On Transmission Of Diseases In Chennai Population. Int J Dentistry Oral Sci. 2019;S5:02:0017:92-99. doi: http://dx.doi.org/10.19070/2377-8075-SI02-050017

Copyright: L. Keerthi Sasanka ${ }^{\circ} 2019$. This is an open-access article distributed under the terms of the Creative Commons Attribution License, which permits unrestricted use, distribution and reproduction in any medium, provided the original author and source are credited. 
mate changes on important and significant zoonoses in India are discussed in many review [20].

The role of ventilation in removing exhaled airborne bio-aerosols and preventing cross infections has been multidisciplinary extensively studied after the SARS outbreak in 2003 which was an unforgettable moment for the people after that year. The characteristics of droplet-borne, short-range airborne and long-range airborne transmission of infectious diseases were identified and also recognised by the people around the world. Increasing ventilation rate can effectively reduce or decrease the high risk of long-range airborne transmission, while it may be of little useful in preventing the droplet-borne transmission. To maintain the airflow direction from clean cubicles to dirty cubicles is an effective way to prevent the cross infection between cubicles, which is widely used in hospital isolation rooms for prevention. Field measurements showed that wrong air flow direction was due to poor construction quality or may be because of maintenance. The impacts of different and various airflow patterns on removing large droplets and fine droplet nuclei were discussed. Some new concepts in general ventilation systems and local personalised equipment were also introduced and were made for people. The reviews updates current knowledge of the airborne transmission of pathogens and the improvement of ventilation efficiency concerning the infection for safety and prevention [15].

An important and dangerous vector borne disease which include Dengue fever, a mosquito-borne viral infection caused by 4 antigenically distinct and various dengue virus serotypes in the family Flaviviridae, is widespread in tropical and subtropical regions; these areas are known for it. Infection is characterized or classified by the abrupt onset of fever, myalgia, fatigue, and headache. Discussion in the use of erythema may be present early in the course of infection, and maculopapular eruption may be present later. Associated complications include dengue shock syndrome and dengue hemorrhagic fever, which are diagnosed on the basis of the presence of severe fever, thrombocytopenia, hemorrhage, and excessive vascular permeability. Laboratory findings commonly include the leukopenia, thrombocytopenia, and abnormalities in the results of the liver function tests [7], one should be very cautious in maintaining a hygienic environment in and around dental clinics which limits mosquito borne diseases. To this end, creating awareness of the disease and its effects on millions of people in the world is critically important [21, 23].

\section{Materials and Methods}

A descriptive cross sectional study was conducted among the chennai population who are randomly chosen. To analyse their awareness in spread of transmission diseases in chennai population. Approval was obtained from the Institutional review board. The survey was conducted among 100 people. Random sampling method was done. Self administrated questionnaire of 15 closed ended questions was prepared and distributed among the participants online through "Google forms". The questionnaire conducted questions are demographic details also. The self administrated questionnaire was prepared and explained well and distributed. Many studies have been done using spss software or analytics in saveetha dental college successfully that have been published $[8,9,16]$. There are also other studies that are conducted using analytical softwares [1, 4]. The datas were collected, compiled, arranged in a systematic manner and analysed in terms of frequencies using SPSS software and pearson chi square test which was done in association with gender and the awareness and knowledge in transmission of diseases. The confidence interval was found to be $95 \%$ and statistically significant of $p<0.05$. The results are then represented as pie charts and bar graphs.

\section{Result and Discussion}

Despite remarkable progress in the air borne, Victor borne and waterborne diseases in India, the morbidity associated with these diseases is still highly increased. Many of these diseases are controllable through awareness and prevention practises in a good manner to avoid diseases. This study was an attempt to evaluate the effectiveness of a prevention care awareness campaign by enhancing knowledge related with airborne, Vector Borne and waterborne diseases, which is dominating the whole world.

Responses were collected and the data was analysed. Majority of the participants were aware of transmission diseases and also they were aware of prevention precautions of airborne diseases while some of them were not aware. The study was conducted among hundred random people of patients who come to dental clinics. The study included 45 female and 55 male participants (figure2), from the age group of 15 to 40 years (figure 1). When they were asked whether they were aware of transmission diseases $43 \%$ responded that they were aware, $57 \%$ responded that they were not aware of transmission diseases (figure 3). When the participants were asked whether they think that the diseases can be transmitted through air or water $51 \%$ agreed that diseases can be transmitted through air or water, $48 \%$ were not aware (figure 4 ).

When they were asked how many routes of transmission there are in $45.5 \%$ responded that their best routes of transmission of diseases, $47.5 \%$ responded that there are five routes of transmis-

Figure 1. The piechart represents the frequency distribution of age groups of the participants, in which $50.51 \%$ (blue) represent $15-20,40.4 \%$ (red) represent $20-30,1 \%$ (green) represent $30-40,8.08 \%$ (orange) represent 70. The majority (50\%) of the people are 15 to 20 years.

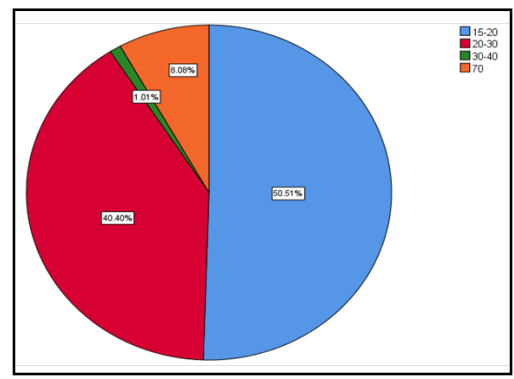


Figure 2. The pie chart represents the frequency distribution of gender of the participants, $54.1 \%$ (blue) represents male, $45.8 \%$ (red) represents female. The Majority $(54.2 \%)$ of the respondents are males.

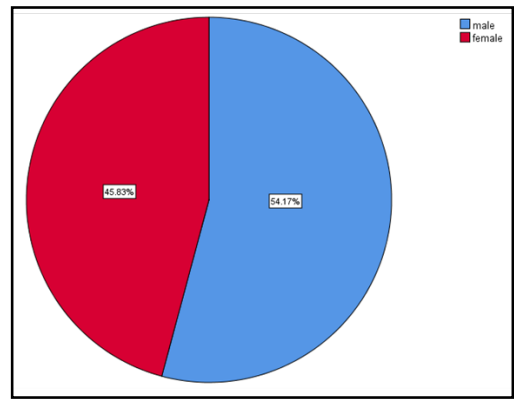

Figure 3. The pie chart represents the frequency distribution of awareness of diseases transmission among people. 57\% (blue) represents that they are aware, $43 \%$ (red) represents that they are not aware. The majority (57\%) of the respondents are aware of transmitted diseases.

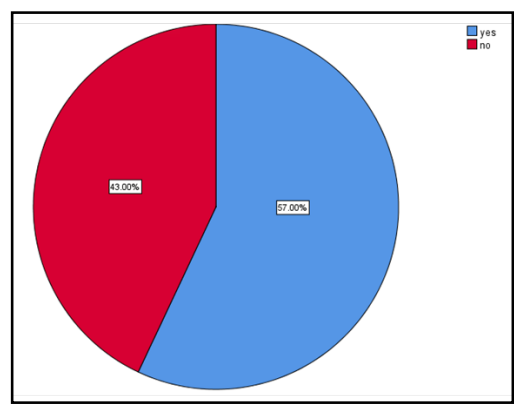

Figure 4. The piechart represents the frequency distribution in awareness of transmission of diseases through air, in which the $52.04 \%$ (blue) represents yes, $47.96 \%$ (red) represents no. The majority (51\%) of the respondents are aware that disease can be spread through air or water.

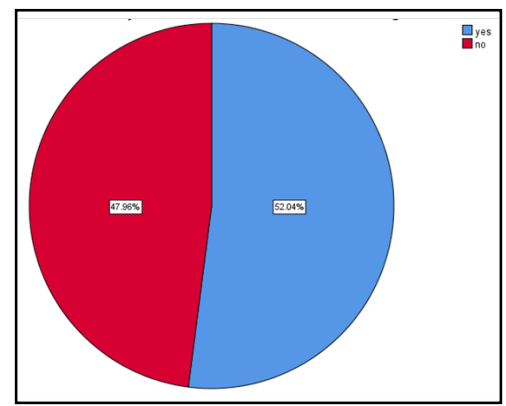

Figure 5. The pie chart represents the frequency distribution of different routes of transmission of diseases in which, $47.47 \%$ (blue) represents $5,45.45 \%$ (red) represents $4,7.07 \%$ (green) represents 6 . The majority $(47.5 \%)$ of respondents responded that there are five routes.

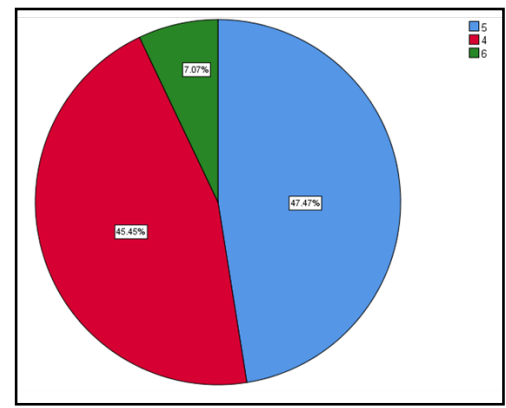

sion, $7.1 \%$ responded that there are six routes of transmission (figure 5). When they were asked what will happen if they drink water with bacteria, 50\% responded that they will get infected, $38 \%$ responded that they'll be healthy, $12 \%$ spotted that they will die. (figure 6). When they were asked how to prevent transmitted disease, $52 \%$ responded that they should get vaccinated, $26.5 \%$ responded that it is good to wash hands of 10, 20.4\% responded that it is good to follow both. (figure 7). When the participants were asked whether it is good for them to use antibiotics or not,
$47.5 \%$ responded that it is not good, $52.5 \%$ responded that it is good(figure 8). When the participants were asked in what way we can create awareness on transmission of disease, $52 \%$ responded that we can create awareness by education, 35\% responded that you can create awareness by giving counselling, 13\% responded that both are good. (figure 9). When the participants were asked which illustrates a vehicle of distance transmission $41.8 \%$ responded that a toilet seat in a public bathroom, $27.6 \%$ responded that a cut on your hand, $22.4 \%$ responded to a sponge soaked in 
Figure 6. The pie chart represents the frequency distribution in prevention of drinking bacteria contaminated water, in which $50 \%$ (blue) represents persons will get infected, $38 \%$ (red) represents persons will be healthy, $12 \%$ (green) represents persons will die.The majority $(50 \%)$ of the respondents are aware that if they drink bacteria contaminated water they will get infected.

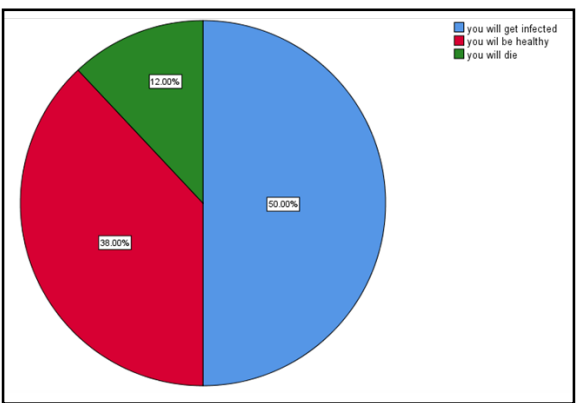

Figure 7. The piechart represents the frequency distribution about prevention of transmitted diseases, in which $53.06 \%($ red) represents washing hands often, $26.53 \%$ (blue) represents vaccination, $20.41 \%$ (green) represents both. The majority (52\%) of the respondents are aware that it is good to get vaccinated in order to prevent diseases.

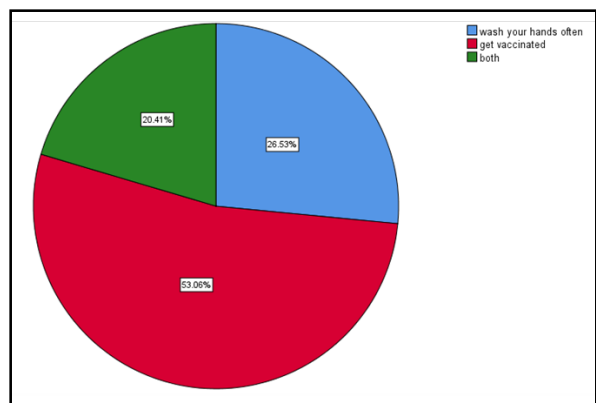

Figure 8. The pie chart represents the frequency distribution about awareness of using antibiotics in which $52.53 \%$ (blue) represents yes, $47.47 \%$ (red) represents no. The majority $(52.5 \%)$ respondents are aware that using antibiotics is good.

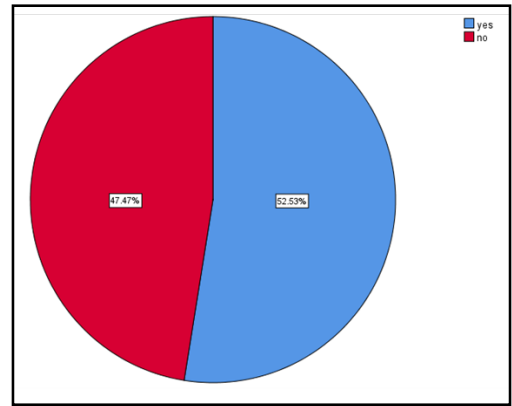

Figure 9. The pie chart represents the frequency distribution in creating awareness in transmission of diseases, in which $52 \%$ (red) represents education, $35 \%$ (blue) represents counseling, $13 \%$ (green) represents both. The majority (52\%) of respondents are aware that awareness on diseases can be given by education.

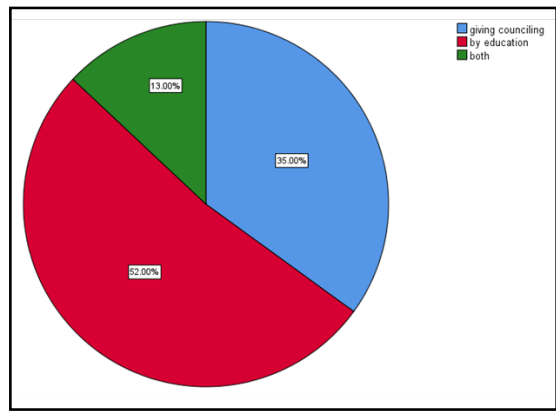

bleach water, $8.2 \%$ responded that the packaged spinach containing E. coli (figure 10).

The graph represents the association between gender and awareness of transmission diseases among people, the $\mathrm{p}$ value was $>0.05$ which is statistically not significant.In both male and female majority of them are aware of transmission diseases (Figure
11). The graph represents the association between gender and awareness whether diseases are transmitted through air, Association between gender and awareness whether diseases are transmitted through air diseases was done using chi square test $\mathrm{p}$ value is $>0.05$ which is statistically not significant.In male majority of them are aware that diseases can also be transmitted through air and in female majority of them are not aware (Figure 12). The 
graph represents the association between gender and number of routes in transmission,was done using chi square test $p$ value is $>0.05$ which is statistically not significant.In male majority of them responded that there are 4 routes and in female majority of them responded as 5 routes (Figure 13). The graph represents the association between gender and the happenings of drinking water with bacteria, was done using chi square test $p$ value is $>0.05$ which is statistically not significant.In male majority of them responded that if they drink bacteria water they will get infected and in female two options are equally answered that they will get infected and the other option is that they will be health (Figure 14). The graph represents the association between gender and ways of prevention in transmission of diseases, was done using chi square test, $\mathrm{p}$ value is $>0.05$ which is statistically not significant.In both male and female majority of them responded that they should get vaccinated is a good way to avoid diseases (Figure 15). The graph represents the association between gender and awareness in usage of antibiotics, was done using chi square test $p$ value is $>0.05$ which is statistically not significant.In male majority of them are not aware of using antibiotics and female majority of them are aware (Figure 16). The graph represents the association between gender and ways of creating prevention of diseases, was done using chi square test $\mathrm{p}$ value is $>0.05$ which is statistically significant. In both male and female majority of them are aware that awareness can be created by education (Figure 17).

Figure 10. The pie chart represents the frequency distribution about following best way of avoiding distance transmission in which $27.55 \%$ (blue) represents cut on the hand, $41.64 \%$ (red) represents a toilet seat in a public bathroom, $22.45 \%$ (green) represents a sponge soaked in bleach water, $8.16 \%$ (orange) represents packaged spinach containing $E$ coli. The majority

$\mathbf{( 4 1 . 8 \% )}$ of respondents are aware that a toilet seat in public bathrooms acts as a vehicle for disease transmission.

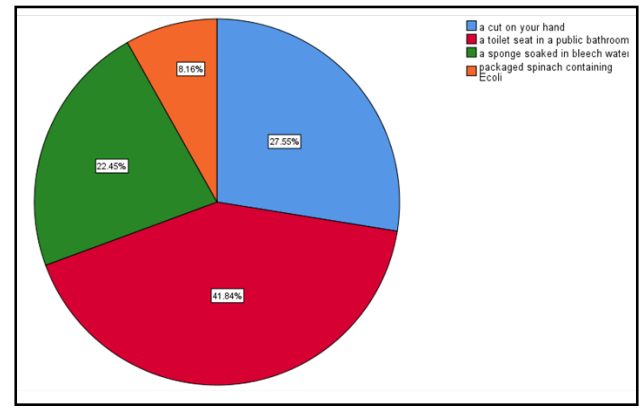

Figure 11. This graph represents the association between gender and awareness of disease transmission among people, $\mathrm{x}$ axis represents the gender and $\mathrm{y}$ axis represents number of participants, blue represents that people are aware, and red represents they are not aware. The association between gender and awareness on transmission diseases was done using chi square test (Pearson's Chi Square test value:0.307, DF value: 1 and $p=0.58 ; p>0.05$ ) which is found to be statistically not significant. In both genders there is a similar level of awareness about transmission of diseases.

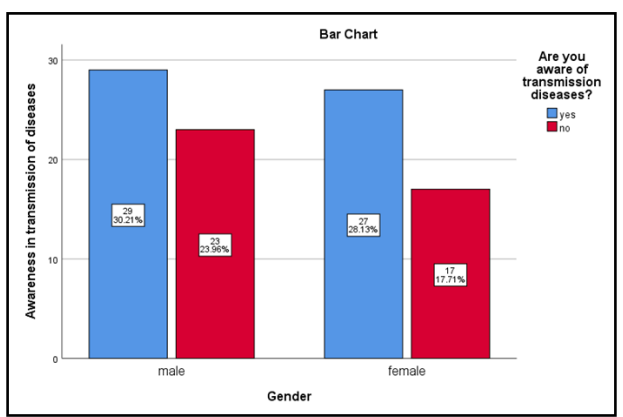

Figure 12. This graph represents the association between gender and awareness whether diseases are transmitted through air,x axis represents gender and $y$ axis represents number of participants blue represents that people are aware,and red represents they are not aware. Association between gender and awareness whether diseases are transmitted through air diseases was done using chi square test (chi square test value:1.989; $\mathrm{d}$ value $=1 ; \mathrm{p}=0.15, \mathrm{p}>0.05$ ) which is found to be statistically not significant.In male majority of them are aware that diseases can also be transmitted through air and in female majority of them are not aware.

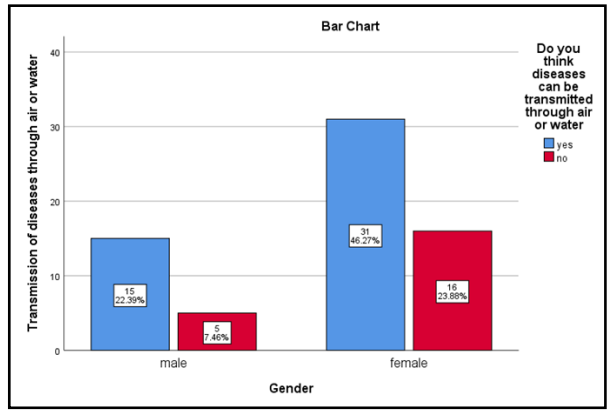


Figure 13. This graph represents the association between gender and number of routes in transmission, $\mathrm{x}$ axis represents the gender and $y$ axis represents number of participants blue represents 5 routes and red represents 4 routes and green represents 5 routes.Association between gender and number of routes in transmission was done using chi square test (chi square test $=0.793 ; \mathrm{d}$ value $=2 ; \mathrm{p}=0.67, \mathrm{p}>0.05$ ) which is found to be statistically not significant.In male majority of them responded that there are 4 routes and in female majority of them responded as 5 routes.

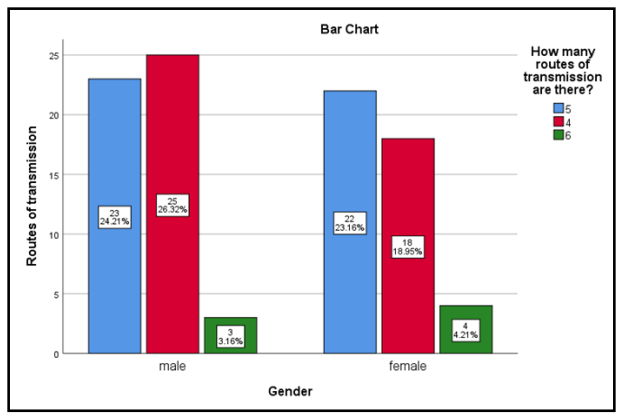

Figure 14. This graph represents the association between gender and the happenings of drinking water with bacteria, $x$ axis represents the gender and $y$ axis represents number of participants blue represents that people will get infected if they drink infected water, red represents that people will be healthy and green represents that people will die. Association between gender and happenings of drinking water with bacteria was done using chi square test (chi square test $=5.593 ; \mathrm{d}$ value $=2 ; \mathrm{p}=0.06, \mathrm{p}>0.05$ ) which is found to be statistically not significant.In male majority of them responded that if they drink bacteria water they will get infected and in female two options are equally answered that they will get infected and the other option is that they will be healthy.

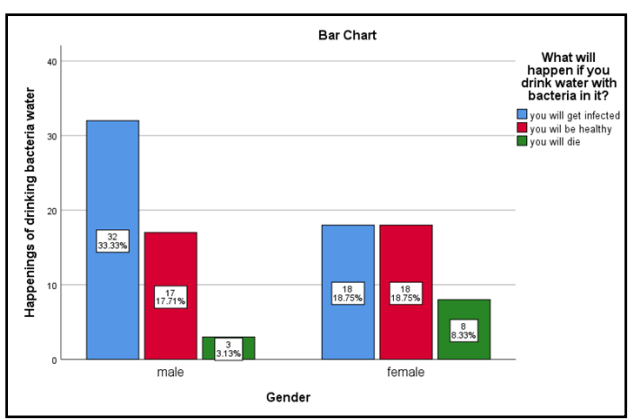

Figure 15. This graph represents the association between gender and ways of prevention in transmission of diseases, $x$ axis represents the gender and $y$ axis represents number of participants, blue represents in washing the hands often, red represents in getting vaccinated and green represents both the above options.Association between gender and ways of prevention in transmission of diseases was done using chi square test (chi square test value $=0.933 ; \mathrm{d}$ value $=2 ; \mathrm{p}=0.62, \mathrm{p}>0.05$ ) which is found to be statistically not significant.In both male and female majority of them responded that they should getting vaccinated is a good way to avoid diseases.

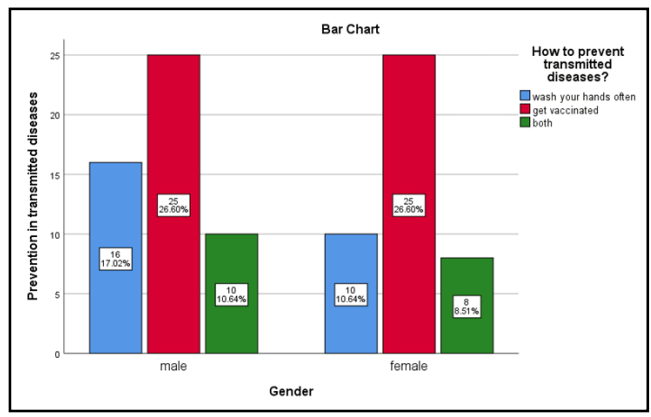

The present research has origins from previous studies, where the investigations involved in studies which were done based on clinical reports, interventional studies $[3,23,11,16,8]$, systematic reviews have also been successfully published in saveetha dental college $[17,20,25,2,5,12]$.

Mobilizing Community based on its health insurance to enhance awareness and prevention of airborne, waterborne and vector borne diseases in rural India increases in our Ness and prevention was 34\% [14]. An elusive pathway of Aragon transmission is very dangerous to human beings when it's not in our control
[6]. Knowledge and attitude among non-healthy science University students needs attention 35.7 percentage students have good knowledge on transmission, when compared to my study the students have knowledge and awareness about transmission diseases [13]. Prevalence of water and vector borne zoonoses increase in coming years due to the effect of global warming [19]. Nosocomial mucocutaneous transmission another roots of transmission are there which are dangerous [7].

Bacteria is the cause of gastric cancer, so prevention of it is important and essential to human beings being alive [6]. The quality 
Figure 16. This graph represents the association between gender and awareness in usage of antibiotics, $x$ axis represents gender and $y$ axis represents number of participants blue represents that people are aware,and red represents they are not aware. Association between gender and awareness in usage of antibiotics was done using chi square test (chi square test value $=9.964 ; \mathrm{d}$ value $=1 ; \mathrm{p}=0.32, \mathrm{p}>0.05$ ) which is found to be statistically not significant. In male majority of them are not aware of using antibiotics and female majority of them are aware.

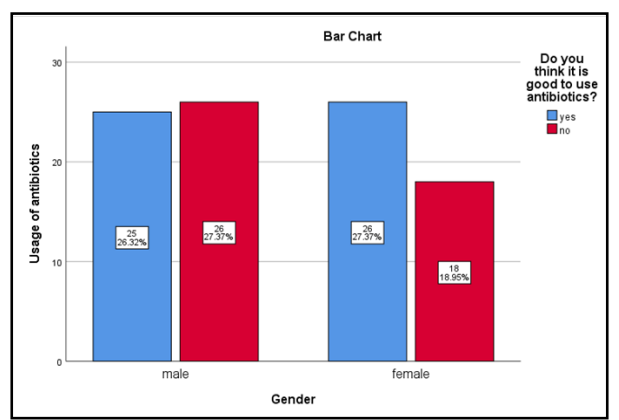

Figure 17. This graph represents the association between gender and ways of creating prevention of diseases, $\mathrm{x}$ axis represents the gender and $y$ axis represents number of participants ,blue represents counseling method, red represents educational method,green represents both.Association between gender and ways of creating prevention in diseases was done using chi square test (chi square test value $=6.600 ; \mathrm{d}$ value $=2 ; \mathrm{p}=0.03, \mathrm{p}>0.05$ ) which is found to be statistically significant.In both male and female majority of them are aware that awareness can be created by education.

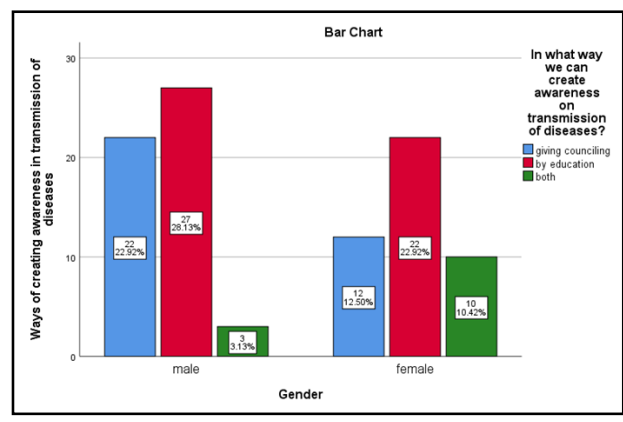

of raw and drinking water considerable concern due to positivity of faecal indicator should be also noted by us [24]. Incidence and trends of infection with pathogens transmitted through food and water should be considered additionally in our knowledge to survive [22]. What prevention in transmission of infection agents in diseases that is harmful should be known because of its harmful effects [18]. Bacteria can also be isolated and cultured and were identified as antibiotics [9]. Importance of awareness and education in prevention and control of RHD [26]. The preventional method can be spotted by people and learnt for living a healthy life and long life [15]. The limitation of the study is homogeneous and should have had more population. Future scope this study can be further preceded by further research and reviews.

\section{Conclusion}

The results suggest that well crafted health and educational campaigns can create a really good awareness among common people worldwide. Health promotion can also be a regular course for detection and prevention of diseases.

\section{Author Contribution}

Author 1 (S. Amrithaashri), carried out the study by collecting data and drafted the manuscript after performing the necessary statistical analysis. Author 2 (Dr. L.Keerthi Sasanka) aided in conception of the topic, has participated in the study design, statistical analysis and has supervised in preparation of the manuscript. Author 3 (Dr. Archana Santhanam) has participated in the study design and has coordinated in developing the manuscript.All the authors have discussed the results among themselves and contributed to the final manuscript.Author 4 (Dr. Subhashree) aided in, methodology and statistical analysis and has supervised in preparation of the manuscript.

\section{Acknowledgement}

This research was done under the supervision of the Department of research of saveetha dental college and hospitals. We sincerely show gratitude to the corresponding guides who provided insight and expertise that greatly assisted the research.

\section{References}

[1]. Ajay R, Suma K, Ali SA, Kumar Sivakumar JS, Rakshagan V, Devaki V, et al. Effect of Surface Modifications on the Retention of Cement-retained Implant Crowns under Fatigue Loads: An In vitro Study. J Pharm Bioallied Sci. 2017 Nov; 9(Suppl 1): S154-S160. PMID: 29284956.

[2]. Jain AR, Nallaswamy D, Ariga P, Ganapathy DM. Determination of correlation of width of maxillary anterior teeth using extraoral and intraoral factors in Indian population: A systematic review. World J Dent. 2018 Jan; 9: 68-75.

[3]. Ashok V, Nallaswamy D, Benazir Begum S, Nesappan T. Lip Bumper Prosthesis for an Acromegaly Patient: A Clinical Report. J Indian Prosthodont Soc. 2014 Dec; 14(Suppl 1): 279-82. PMID: 26199531.

[4]. Ashok V, Suvitha S. Awareness of all ceramic restoration in rural population. Research Journal of Pharmacy and Technology. 2016; 9(10): 1691-3.

[5]. Basha FYS, Ganapathy D, Venugopalan S. Oral Hygiene Status among Pregnant Women.Research Journal of Pharmacy and Technology. 2018; 11(7): 3099-3102.

[6]. Boehnke KF, Brewster RK, Sánchez BN, Valdivieso M, Bussalleu A, Guevara 
$\mathrm{M}$, et al. An assessment of drinking water contamination with Helicobacter pylori in Lima, Peru. Helicobacter. 2018 Apr; 23(2): e12462. PMID: 29316052.

[7]. Chen LH, Wilson ME. Transmission of dengue virus without a mosquito vector: nosocomial mucocutaneous transmission and other routes of transmission. Clin Infect Dis. 2004 Sep 15; 39(6): e56-60. PMID: 15472803.

[8]. Duraisamy R, Krishnan CS, Ramasubramanian H, Sampathkumar J, Mariappan S, Navarasampatti Sivaprakasam A. Compatibility of Nonoriginal Abutments With Implants: Evaluation of Microgap at the Implant-Abutment Interface, With Original and Nonoriginal Abutments. Implant Dent. 2019 Jun;28(3):289-295. PMID: 31124826.

[9]. Ganapathy D, Sathyamoorthy A, Ranganathan H, Murthykumar K. Effect of Resin Bonded Luting Agents Influencing Marginal Discrepancy in All Ceramic Complete Veneer Crowns. J Clin Diagn Res. 2016 Dec;10(12):ZC67ZC70. PMID: 28209008.

[10]. Kannan A. Effect of Coated Surfaces influencing Screw Loosening in Implants: A Systematic Review and Meta-analysis. World. 2017 Nov;8(6):496502.

[11]. Jyothi S, Robin PK, Ganapathy D. Periodontal health status of three different groups wearing temporary partial denture. Research Journal of Pharmacy and Technology. 2017;10(12):4339-42.

[12]. Kannan A, Venugopalan S. A systematic review on the effect of use of impregnated retraction cords on gingiva. Research Journal of Pharmacy and Technology. 2018;11(5):2121-6.

[13]. Mekonnen A, Collins JM, Klinkenberg E, Assefa D, Aseffa A, Ameni G, et al. Tuberculosis knowledge and attitude among non-health science university students needs attention: a cross-sectional study in three Ethiopian universities. BMC Public Health. 2020 May 6;20(1):631. PMID: 32375716.

[14]. Panda P, Chakraborty A, Dror DM. Mobilizing community-based health insurance to enhance awareness \& prevention of airborne, vector-borne \& waterborne diseases in rural India. Indian J Med Res. 2015 Aug;142(2):15164. PMID: 26354212

[15]. Qian H, Zheng X. Ventilation control for airborne transmission of human exhaled bio-aerosols in buildings. J Thorac Dis. 2018 Jul;10(Suppl 19):S2295-S2304. PMID: 30116608.
[16]. Ranganathan H, Ganapathy DM, Jain AR. Cervical and Incisal Marginal Discrepancy in Ceramic Laminate Veneering Materials: A SEM Analysis. Contemp Clin Dent. 2017 Apr-Jun;8(2):272-278. PMID: 28839415.

[17]. Selvan SR, Ganapathy D. Efficacy of fifth generation cephalosporins against methicillin-resistant Staphylococcus aureus-A review. Research Journal of Pharmacy and Technology. 2016;9(10):1815-8.

[18]. Siegel JD, Rhinehart E, Jackson M, Chiarello L. Health Care Infection Control Practices Advisory Committee. 2007 Guideline for Isolation Precautions: Preventing Transmission of Infectious Agents in Health Care Settings. Am J Infect Control. 2007 Dec;35(10 Suppl 2):S65-164. PMID: 18068815.

[19]. Singh BB, Sharma R, Gill JP, Aulakh RS, Banga HS. Climate change, zoonoses and India. Rev Sci Tech. 2011 Dec;30(3):779-88. PMID: 22435190.

[20]. Subasree S, Murthykumar K. Effect of Aloe Vera in Oral Health-A Review. Research Journal of Pharmacy and Technology. 2016;9(5):609-12.

[21]. Sutter R, Rüegg S, Tschudin-Sutter S. Seizures as adverse events of antibiotic drugs: A systematic review. Neurology. 2015 Oct 13;85(15):1332-41. PMID: 26400582

[22]. Tack DM, Marder EP, Griffin PM, Cieslak PR, Dunn J, Hurd S, et al. Preliminary Incidence and Trends of Infections with Pathogens Transmitted Commonly Through Food - Foodborne Diseases Active Surveillance Network, 10 U.S. Sites, 2015-2018. MMWR Morb Mortal Wkly Rep. 2019 Apr 26;68(16):369-373. PMID: 31022166

[23]. Venugopalan S, Ariga P, Aggarwal P, Viswanath A. Magnetically retained silicone facial prosthesis. Niger J Clin Pract. 2014 Mar-Apr;17(2):260-4. PMID: 24553044

[24]. Vesga FJ, Moreno Y, Ferrús MA, Ledesma-Gaitan LM, Campos C, Trespalacios AA. Correlation among fecal indicator bacteria and physicochemical parameters with the presence of Helicobacter pylori DNA in raw and drinking water from Bogotá, Colombia. Helicobacter. 2019 Jun;24(3):e12582. PMID: 30950129.

[25]. Vijayalakshmi B, Ganapathy D. Medical management of cellulitis. Research Journal of Pharmacy and Technology. 2016;9(11):2067-70.

[26]. Zühlke LJ, Engel ME. The Importance of Awareness and Education in Prevention and Control of RHD. Glob Heart. 2013 Sep;8(3):235-9. PMID: 25690501. 